Article

\title{
Inter-Calibration of Passive Microwave Satellite Brightness Temperatures Observed by F13 SSM/I and F17 SSMIS for the Retrieval of Snow Depth on Arctic First-Year Sea Ice
}

\author{
Qingquan Liu ${ }^{1}$, Qing Ji ${ }^{1,2, *}\left(\mathbb{D}\right.$, Xiaoping Pang ${ }^{1,2}$, Xin Gao ${ }^{3}$, Xi Zhao ${ }^{1,2}$ and Ruibo Lei ${ }^{4}$ \\ 1 Chinese Antarctic Center of Surveying and Mapping, Wuhan University, Wuhan 430079, China; \\ lqqgis@whu.edu.cn (Q.L.); pxp@whu.edu.cn (X.P.); xi.zhao@whu.edu.cn (X.Z.) \\ 2 Key Laboratory of Polar Surveying and Mapping, National Administration of Surveying, \\ Mapping and Geoinformation, Wuhan 430079, China \\ 3 School of Resource and Environmental Sciences, Wuhan University, Wuhan 430079, China; \\ serigo@whu.edu.cn \\ 4 Key Laboratory for Polar Science of the State Oceanic Administration, Polar Research Institute of China, \\ Shanghai 200136, China; leiruibo@pric.org.cn \\ * Correspondence: jiqing@whu.edu.cn; Tel.: +86-135-5405-1047
}

Received: 6 November 2017; Accepted: 23 December 2017; Published: 26 December 2017

\begin{abstract}
Passive microwave satellite brightness temperatures (TB) that were observed by the F13 Special Sensor Microwave/Imager (SSM/I) and the subsequent F17 Special Sensor Microwave Imager/Sounder (SSMIS) were inter-calibrated using empirical relationship models during their overlap period. Snow depth (SD) on the Arctic first-year sea ice was further retrieved. The SDs derived from F17 TB and F13C TB which were calibrated F17 TB using F13 TB as the baseline were then compared and evaluated against in situ SD measurements based on the Operational IceBridge (OIB) airborne observations from 2009 to 2013. Results show that Cavalieri inter-calibration models (CA models) perform smaller root mean square error (RMSE) than Dai inter-calibration models (DA models), and the standard deviation of OIB SDs in the $25 \mathrm{~km}$ pixels is around $6 \mathrm{~cm}$ on first-year sea ice. Moreover, the SDs derived from the calibrated F17 TB using F13 TB as the baseline were in better agreement than the F17 SDs as compared with OIB SDs, with the biases of $-2 \mathrm{~cm}$ (RMSE of $5 \mathrm{~cm}$ ) and $-9 \mathrm{~cm}$ (RMSE of $10 \mathrm{~cm}$ ), respectively. We conclude that TB observations from F17 SSMIS calibrated to F13 SSM/I as the baseline should be recommended when performing the sensors' biases correction for SD purpose based on the existing algorithm. These findings could serve as a reference for generating more consistent and reliable $\mathrm{TB}$, which could help to improve the retrieval and analysis of long-term snow depth on the Arctic first-year sea ice.
\end{abstract}

Keywords: snow depth; SSM/I; SSMIS; Operation IceBridge; Arctic

\section{Introduction}

The Arctic has undergone rapid change over recent decades [1,2]. Sea ice in the Arctic is decreasing at an accelerated rate [3,4], shifting from multiyear ice to younger ice $[5,6]$. Snow is the primary atmospheric source input to Arctic sea ice, and it is highly sensitive to climate change [7]. The snow cover on sea ice possesses several typical characteristics, such as a high albedo and low thermal conductivity, which influences the heat transfer between the ocean and the atmosphere [8-10]. Furthermore, snow depth (SD) on sea ice is vital to understanding the overall heat exchange occurring in the Polar Regions, and also important variables in the fresh water budget of the oceans. Additionally, accurate estimation of the snow depth is essential for calculating sea-ice thickness and volume $[11,12]$. 
Research has shown that a SD uncertainty of $5 \mathrm{~cm}$ could lead to estimation errors of $35 \mathrm{~cm}$ in the ice thickness [13].

The Special Sensor Microwave/Imager (SSM/I) and the Special Sensor Microwave Imager/Sounder (SSMIS) on Defense Meteorological Satellite Program (DMSP) satellites provide brightness temperature (TB) data for the retrieval of SD on sea ice at a large spatial and temporal scale $[8,10]$. These data make it possible to study the spatiotemporal variability of SD on Arctic sea ice. However, the agreement and consistency of the TB measurements are affected by the differences in satellite sensors and platforms, which lead to discrepancies in the derived long-term SD on sea ice.

Inter-calibration and validation are fundamental assurances for the application of remote sensing data $[14,15]$. Cross-platform calibrations have been performed between the SSM/I carried on the DMSP-F8, DMSP-F11 (SSM/I) and DMSP-F13 (SSM/I). Abdalati et al. [16] examined the correlation between F8 and F11 SSM/I TB, and a further study by Stroeve et al. [17] indicated that the differences among F8, F11, and F13 data are sufficiently large to affect analyses of sea-ice extent and area time-series data. Meier et al. [18] and Cavalier et al. [19] used the full-year F13 SSM/I and F17 SSMIS overlap TB data, to obtain consistent sea ice extent and area information based on intercalibration processing. Dai et al. [20] inter-calibrated TB data obtained from different passive microwave satellite sensors, and assessed the consistency of terrestrial snow depth retrievals in China. However, there has been no adequate comparison and evaluation between the retrieved SDs from F13 SSM/I and F17 SSMIS, and the intercalibration effects in terms of SD retrievals on the Arctic sea ice during their overlap period.

In this paper, the differences between the estimated SDs based on the original F17 SSMIS TB and the calibrated F17 SSMIS TB using the F13 SSM/I TB as the baseline are assessed through comparing with the Operation IceBridge (OIB) SD measurements. We also analyzed the performance of different inter-calibration models according to the method of Cavalieri and Dai, and made the assessment of OIB SD data which were resampled to a pixel size of $25 \mathrm{~km}$ on first-year sea ice.

\section{Study area and Data}

\subsection{Region of Interest}

The variation of Arctic snow cover is sensitive to climate change, especially in the marginal sea ice areas [21]. The region of concern of this study is the Arctic Ocean within the latitudinal range from $66^{\circ} 33^{\prime} \mathrm{N}$ to $90^{\circ} \mathrm{N}$ (Figure 1).

\subsection{SSM/I and SSMIS Data}

Passive microwave (PM) remote sensing possesses the advantage of penetration through most clouds and operates well in day and night. This allows large-scale detection the Earth's surface, even in Polar Regions. A continuous time series of SSM/I TB and SSMIS TB are provided by a series of satellites (Table 1) developed and operated by the Defense Meteorological Satellite Program (DMSP). Considering the temporal coverage of satellites and the similarity of the orbital parameters, and ascending node crossing time (ANCT) $[18,19]$, the TB data of similar orbital parameters of F13 and F17 are chosen for this study, and the daily averaged TB data with a land mask were obtained from the National Snow and Ice Data Center (NSIDC) [22].

These data contain multiple channel microwave TB of 19, 37, and $85 \mathrm{GHz}$ for both horizontal $(\mathrm{H})$ and vertical $(\mathrm{V})$ polarizations, and $22 \mathrm{GHz}$ at vertical polarization $(22 \mathrm{~V})$. The measurement footprint size or effective field of view (FOV) of those channels are described in Table 2, and the spatial resolution were resampled by NSIDC to a pixel size of $25 \mathrm{~km}$. The F13 SSM/I provided brightness temperature measurements from May 1995 to April 2009, while the F17 SSMIS has been operational since December 2006. 


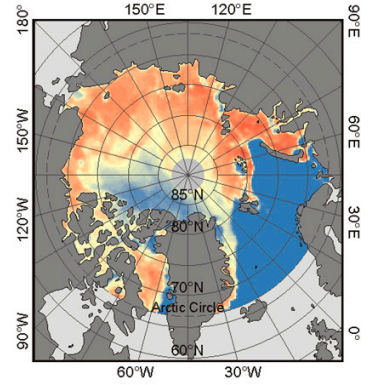

F13 TB19H

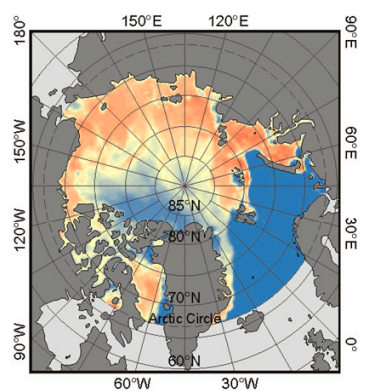

F17 TB19H

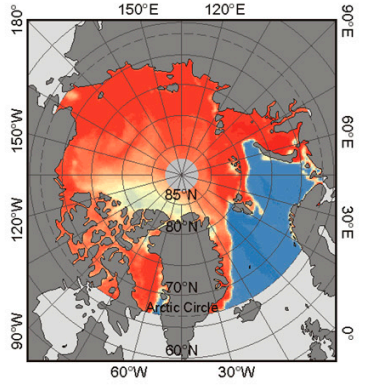

F13 TB19V

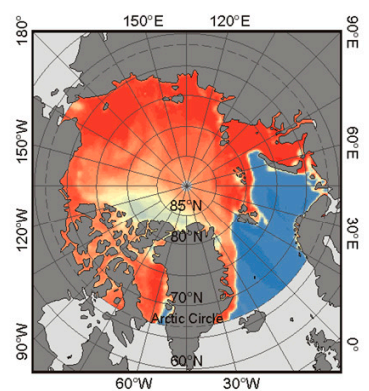

F17 TB19V

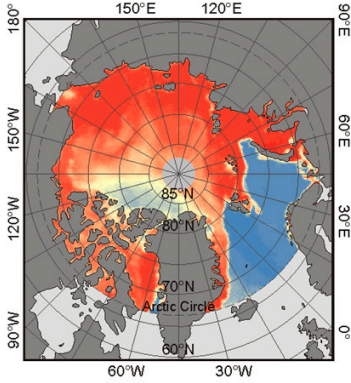

F13 TB22V

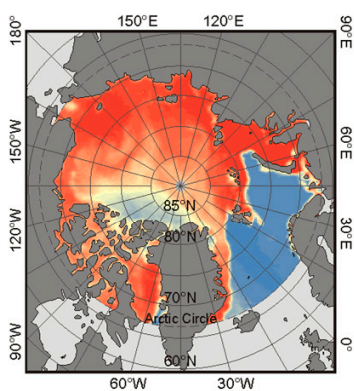

F17 TB22V

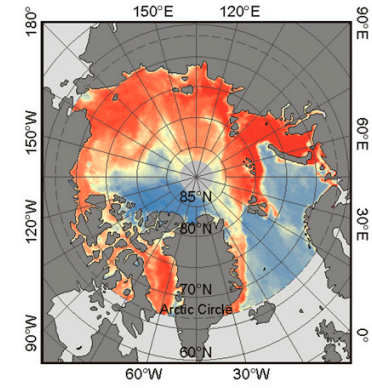

F13 TB37V

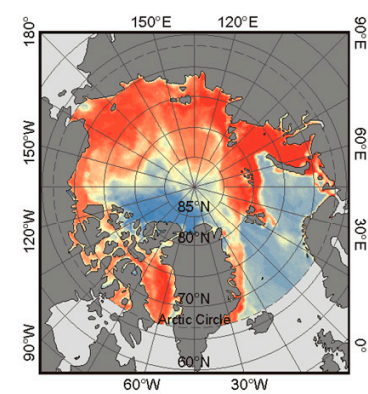

F17 TB37V

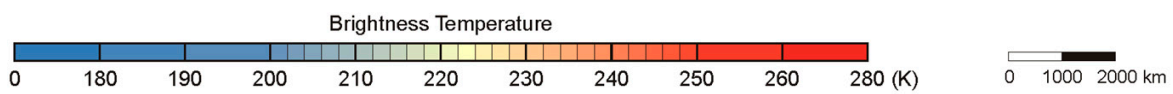

Figure 1. Study area overlapped with F13 SSM/I brightness temperatures and F17 SSMIS brightness temperatures (for the channel of 19H, 19V, 22V, 37V) on 20 March 2007.

Table 1. Satellite parameters of DMSP with SSM/I and SSMIS.

\begin{tabular}{cccccc}
\hline \multirow{2}{*}{ Satellite Parameters } & \multicolumn{3}{c}{ SSM/I } & \multicolumn{2}{c}{ SSMIS } \\
\cline { 2 - 5 } & DMSP-F13 & DMSP-F14 & DMSP-F15 & DMSP-F16 & DMSP-F17 \\
\hline Inclination & $98.8^{\circ}$ & $98.9^{\circ}$ & $98.8^{\circ}$ & $98.9^{\circ}$ & $98.8^{\circ}$ \\
ANCT & $17: 42$ & $16: 45$ & $21: 10$ & $21: 32$ & $17: 31$ \\
Period (minutes) & 102.0 & 101.8 & 101.8 & 101.0 & 102.0 \\
\hline
\end{tabular}

Table 2. Effective field of view (FOV) for SSM/I and SSMIS channels and their resampled grid size.

\begin{tabular}{ccccccc}
\hline \multicolumn{2}{c}{ F13-SSM/I } & \multicolumn{2}{c}{ F17-SSMIS } & \multicolumn{2}{c}{ NSIDC Polar Stereographic Projection Grid } \\
\hline Channel & FOV $\mathbf{( k m )}$ & Channel & FOV $\mathbf{( k m )}$ & Rows & Columns & Pixel Size (km) \\
\hline $19.350 \mathrm{H}$ & $69.7 \times 43.7$ & $19.350 \mathrm{H}$ & $70.1 \times 42.4$ & 448 & 304 & 25 \\
$19.350 \mathrm{~V}$ & $68.9 \times 44.3$ & $19.350 \mathrm{~V}$ & $70.1 \times 42.4$ & 448 & 304 & 25 \\
$22.235 \mathrm{~V}$ & $59.7 \times 39.6$ & $22.235 \mathrm{~V}$ & $70.1 \times 42.4$ & 448 & 304 & 25 \\
$37.000 \mathrm{~V}$ & $35.4 \times 29.2$ & $37.000 \mathrm{~V}$ & $44.2 \times 27.5$ & 448 & 304 & 25 \\
\hline
\end{tabular}

\subsection{OIB Snow Depth Data}

The Operation IceBridge (OIB) mission was initiated to bridge between ICESat-1 and ICESat-2 schedule to be launched in late 2018. At the same time, it monitors SD on Arctic sea ice with the University of Kansas' ultra wideband frequency-modulated continuous wave (FMCW) snow radar. The SD retrieval methods from the snow radar measurements have been described by Kurtz and Farrell [23], and Kurtz et al. [24]. Moreover, the uncertainty of OIB SD retrievals is $5.7 \mathrm{~cm}$, which is based on the comparison with in situ measurements in April 2009 [24].

In this study, the daily OIB SD product [25] distributed by NSIDC was used to compare with the SD derived from PM brightness temperatures from 2009 to 2013. 


\section{Methods}

\subsection{Flow of Data Processing}

As shown in Figure 2, we make the inter-sensor bias correction of the F17 TB data using F13 TB as the baseline sensor, then we get the calibrated TB data denoted as the $\mathrm{F} 13 \mathrm{C} \mathrm{TB}$, and these data are used to calculate SD as well as F17 TB data from 2009 to 2013. The F13C SDs and F17 SDs were then compared with OIB SDs. Inter-calibration methods and models using F13 TB as the baseline are described in Section 3.2. The Section 3.3 describes the SD algorithm using PM TB data, and Section 3.4 presents the method of comparing PM TB derived SD with OIB SD within the daily $25 \mathrm{~km}$ NSIDC polar-stereographic grid.

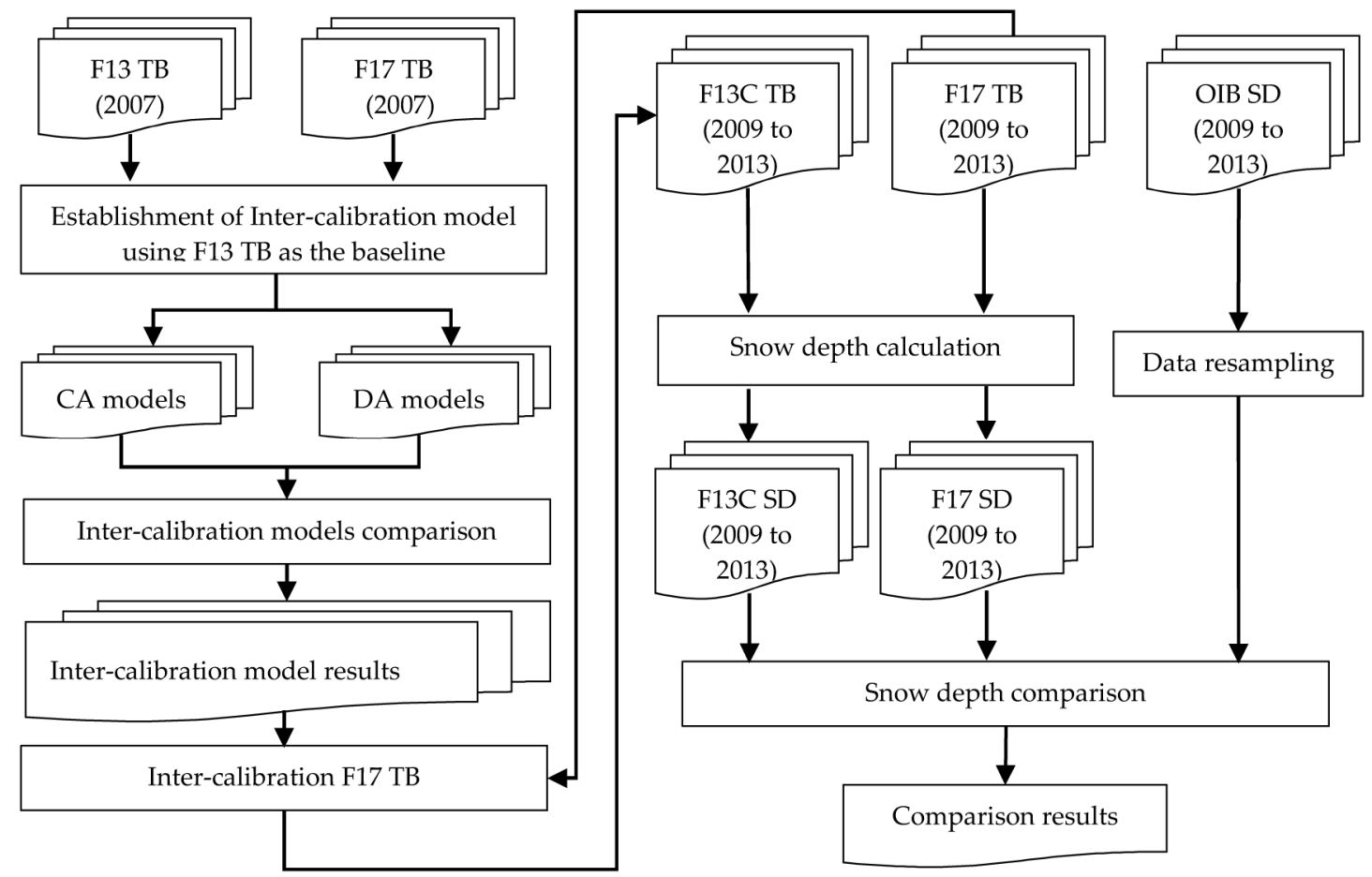

Figure 2. Flow chart of processing, the number in the parentheses represents the year of the data.

\subsection{F13 and F17 Data Inter-Calibration}

Inherent systematic biases between the data acquired by different sensors at the same location $[17,20]$ mean that the inter-calibration is usually required to construct a consistent time-series data set. The overlap period between the F13 SSM/I and the F17 SSMIS from December 2006 to April 2009. When considering the recommendations of NSIDC about the quality and reliability of these data, the brightness temperatures from both of the sensors throughout 2007 were selected to build the calibration models in two methods. The first method follows Cavalieri et al. [18,19]. The linear regression coefficients (slope and intercept) between the F13 TB and F17 TB for each day on each channel $(19 \mathrm{H}, 19 \mathrm{~V}, 22 \mathrm{~V}$ and $37 \mathrm{~V})$ were calculated according to Equation (1).

$$
Y=\text { Slope } \times X+\text { Intercept }
$$

where $Y$ is the daily TB of F13 and $X$ is the daily TB of F17, and then the daily coefficients were averaged to produce the calibration models (henceforth called CA models).

Another method is according to Dai et al. [20]. Linear regression coefficients between F13 TB and F17 TB for each channel were also calculated, according to the Equation (1). However, unlike CA models, $Y$ and $X$ represent F13 TB and F17 TB for the entire year point-pairs on each 
channel, and the calibration models (henceforth called DA models) were then built according to the calculated coefficients. It is important to note that we filtered all daily TB with a land mask provided by NSIDC before inter-calibration.

\subsection{Snow Depth Algorithm}

A close relationship exists between the thickness of the snow cover on first-year sea ice and the TB obtained by a passive microwave satellite radiometer. Based on this relationship, Markus and Cavalieri [8] developed a snow depth retrieval algorithm for first-year sea ice based on DMSP SSM/I data, which they tested in both Arctic and Antarctic seas [26]. We applied this method and calculated snow depth using the vertical gradient ratio of the brightness temperature from $19 \mathrm{~V}$ and $37 \mathrm{~V}$ channels according to:

$$
h_{\mathrm{s}}=\alpha+\beta \cdot G R V(\text { ice })
$$

where, $h_{s}(\mathrm{~cm})$ is the snow depth, $\alpha=-2.34$ and $\beta=-771$ are the coefficients obtained from the linear regression method [8], and GRV (ice) is the vertical gradient ratio, which is calculated based on the brightness temperature (TB) from $19 \mathrm{~V}$ and $37 \mathrm{~V}$ channels. Calculation of the $G R V$ (ice) follows the equation:

$$
G R V(\text { ice })=\frac{T_{B}(37 \mathrm{~V})-T_{B}(19 \mathrm{~V})-k^{-}(1-C)}{T_{B}(37 \mathrm{~V})+T_{B}(19 \mathrm{~V})-k^{+}(1-C)}
$$

where, $k^{-}=T_{\text {Bow }}(37 \mathrm{~V})-T_{\text {Bow }}(19 \mathrm{~V}), k^{+}=T_{\text {Bow }}(37 \mathrm{~V})+T_{\text {Bow }}(19 \mathrm{~V})$, and the open water brightness temperature $T_{\text {Bow }}$ are the tie point values from open water and are used as constants, $T_{\text {Bow }}(19 \mathrm{~V})=185.2 \mathrm{~K}$ and $T_{\text {Bow }}(37 \mathrm{~V})=205.2 \mathrm{~K}$ for F13, whereas, $T_{\text {Bow }}(19 \mathrm{~V})=184.9 \mathrm{~K}$ and $T_{\text {Bow }}(37 \mathrm{~V})=207.1 \mathrm{~K}$ for F17 [19]. $C$ is the sea ice concentration (SIC). In this paper, we calculated SIC of F17 and F13 based on NASA Team (NT) algorithm using the TB of the 19H, 19V, 22V and 37V channels [27], respectively. Furthermore, TB $(22 \mathrm{~V})$ was used to make the weather filters in the NT algorithm. It should be noted that brightness temperatures observed by F13 and F17 are used to calculate SIC, respectively, and the bias and RMSE of SIC between F13 and F17 are $0.5 \%$ and $0.6 \%$.

Based on the SIC and the TB measured by passive microwave satellite, daily SD was retrieved. A five-day running average was made to eliminate short-term effects from weather events or the melt events $[8,28]$ and this running average method was used by NASA to retrieve the northern hemisphere snow depth from early SMMR and SSM/I [29]. It is worth mentioning that the retrieved $\mathrm{SD}$ is inaccurate over multi-year sea ice (MYI) as the microwave signature of snow is very similar to the multiyear ice signature, therefore, we use 100\% first-year SIC based on NT algorithm to get SD on first-year sea ice (FYI). Meanwhile, this SD retrieval algorithm breaks down in May-June when the snow is wet or has a certain liquid water fraction.

\subsection{Snow Depth Comparison}

To compare the snow depth derived from calibrated F13 SSM/I and F17 SSMIS TB data with the OIB snow depth, we used the average bias (B), the root mean square error (RMSE) as the statistical indicator.

Because of the inherent limitation of snow depth algorithm being restricted to the areas of seasonal sea ice $[8,28]$, we obtained daily OIB snow depth data according to $100 \%$ first-year SIC for NT algorithm, and compared with the original F17 SD, and the F13C SD which was derived from F13C TB on first-year sea ice.

There were two objectives to these comparisons: (1) to assess the quality and the accuracy of the retrieved snow depth based on TB data from F13 and F17, and (2) to provide the optimum calibration option for calculating long time series of snow depth on first-year sea ice. 


\section{Results}

\subsection{Inter-Calibration Models}

The overlap period of 2007 was selected for both F13 SSM/I and F17 SSMIS data to establish calibration models using F13 as the baseline with the linear regression relationship in two ways. Table 3 shows the CA models and the DA models for the four channels. All the models were statistically significant at the 0.05 alpha level using F-test.

As shown in Table 3, the slope values are within 0.04 of 1 and the intercepts of $19 \mathrm{H}$ are close to $-2 \mathrm{~K}$ for both models. Moreover, intercept values of $19 \mathrm{~V}$ and $22 \mathrm{~V}$ are less than intercept of the other channels. Comparison of the RMSE for the CA and the DA models show that there are relatively higher values for DA models than that for the CA models for the $19 \mathrm{H}, 19 \mathrm{~V}$ and $22 \mathrm{~V}$ channel, whereas those values of CA models are higher than the DA models for the 37V channel. When considering the overall effect, we used CA models to correct the inter-sensor bias using F13 as the baseline, and obtained the calibrated data denoted as F13C.

Table 3. The regression coefficients of the calibration models $(Y=$ Slope $\times X+$ Intercept $)$ of inter-sensor bias correction using F13 as the baseline.

\begin{tabular}{ccccc}
\hline Channel & Slope & Intercept (K) & RMSE (K) & $\boldsymbol{R}^{\mathbf{2}}$ \\
\hline \multicolumn{5}{c}{ CA models according to Cavalieri et al. [19] } \\
\hline $19 \mathrm{H}$ & 1.020 & -1.562 & 2.44 & 0.998 \\
$19 \mathrm{~V}$ & 1.039 & -6.946 & 2.19 & 0.996 \\
$22 \mathrm{~V}$ & 1.033 & -6.665 & 1.13 & 0.995 \\
$37 \mathrm{~V}$ & 1.019 & -5.646 & 1.44 & 0.992 \\
\hline \multicolumn{5}{c}{ DA models according to Dai et al. [20] } \\
\hline $19 \mathrm{H}$ & 1.023 & -2.046 & 2.53 & 0.998 \\
$19 \mathrm{~V}$ & 1.043 & -7.585 & 2.19 & 0.996 \\
$22 \mathrm{~V}$ & 1.037 & -7.534 & 1.18 & 0.995 \\
$37 \mathrm{~V}$ & 1.006 & -2.636 & 1.38 & 0.994 \\
\hline
\end{tabular}

\subsection{OIB Snow Depth Resampling in $25 \mathrm{~km}$ Pixel}

The spatial coverage for the OIB snow depth includes Beaufort Sea, North of the Canadian archipelago and Greenland in Arctic with the track resolution of $40 \mathrm{~m}$, and the snow depth of OIB measures were distributed not only on first-year ice, but on multiyear ice.

In this study, we selected OIB SD measurements which are distributed in the $25 \mathrm{~km}$ pixels of the $100 \%$ first-year sea ice regions according to the NT algorithm. Although OIB SD measurements have a higher spatial resolution, it is important to evaluate OIB SD transect across the resampling pixel. If there are no less than two OIB transects within a pixel along different routes in one day, we then analyzed the differences of OIB SDs within the pixel.

On 15 March 2012, there are two pixels over first-year sea ice (P1 and P2, Figure 3a). The mean SD varies about $1 \mathrm{~cm}$ in both pixels between the top transect and the bottom transect. On 17 March 2012, only one pixel with two OIB SD transects on first-year sea ice (P3, Figure 3b), the differences of the mean SDs is $2 \mathrm{~cm}$. Therefore, there is $1-3 \mathrm{~cm}$ SD deviation for two transects in different locations in P1-P3 pixels (Table 4).

Table 4. OIB SD statistics within three $25 \mathrm{~km}$ pixels (P1, P2 and P3 in Figure 2). SD mean and STD are the mean value and the standard deviation and of OIB SDs.

\begin{tabular}{ccccccc}
\hline \multirow{2}{*}{$\begin{array}{c}\text { Statistical } \\
\text { Indicator }\end{array}$} & \multicolumn{2}{c}{ 20120315-P1 } & \multicolumn{2}{c}{ 20120315-P2 } & \multicolumn{2}{c}{ 20120317-P3 } \\
\cline { 2 - 6 } & Top Track & Bottom Track & Top Track & Bottom Track & Top Track & Bottom Track \\
\hline SD $D_{\text {mean }}(\mathrm{cm})$ & 16.6 & 17.4 & 12.0 & 11.3 & 15.0 & 12.5 \\
STD $(\mathrm{cm})$ & 6.6 & 7.2 & 4.7 & 5.0 & 6.7 & 7.2 \\
\hline
\end{tabular}


a)
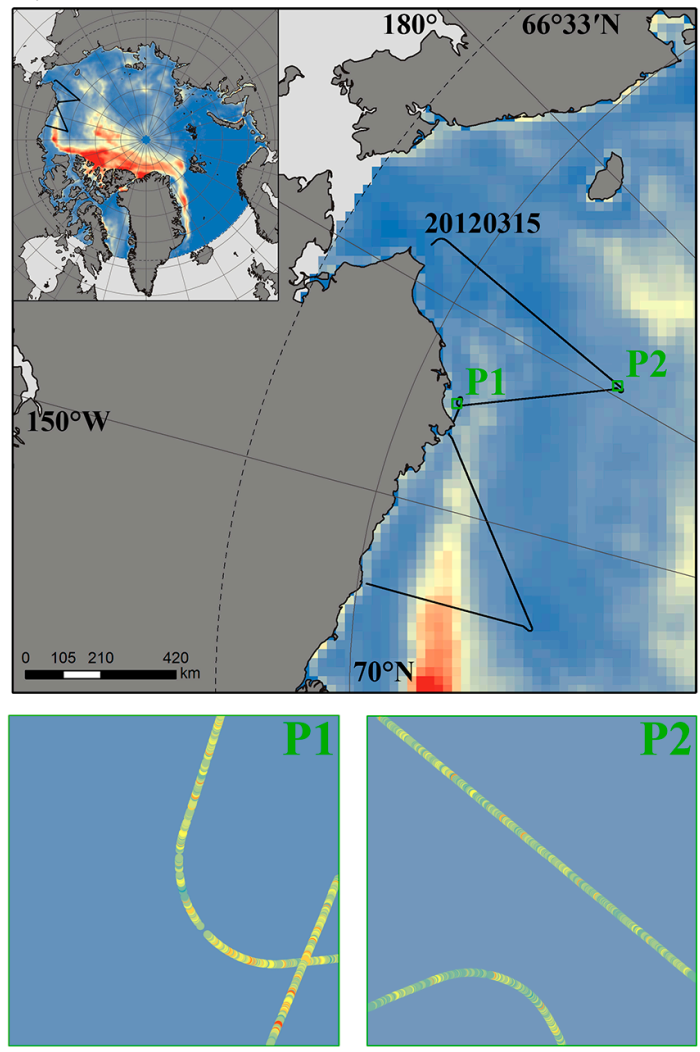

b)
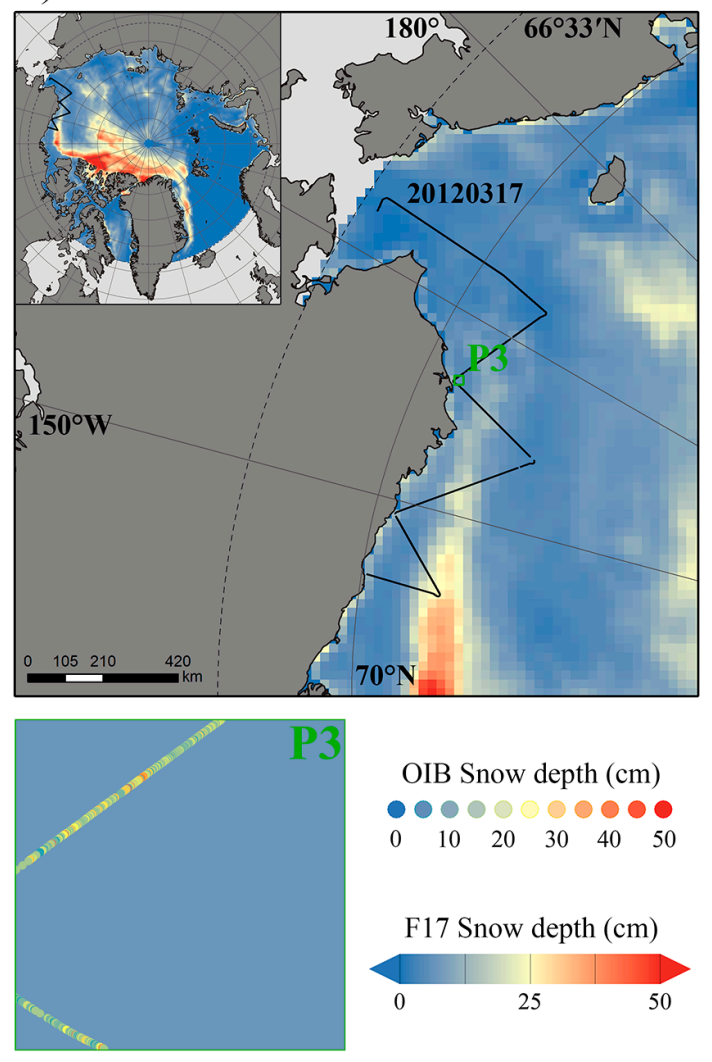

OIB Snow depth (cm) 00000000000 $\begin{array}{llllll}0 & 10 & 20 & 30 & 40 & 50\end{array}$

F17 Snow depth $(\mathrm{cm})$

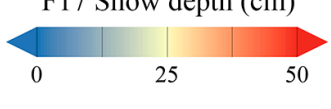

Figure 3. Transects of OIB SD measurements on $100 \%$ first-year sea ice. The background represents the F17 SD at $25 \mathrm{~km}$ resolution. (a) represents the transects on 15 March 2012, north of the Alaska, and the two transects across the F17 SD $25 \mathrm{~km}$ pixels (referenced P1 and P2); (b) represents the transects on 17 March 2012, north of the Alaska, and the two transects across the F17 SD 25 km pixel (referenced P3).

\subsection{Comparison with OIB Snow Depth}

The F17 SSMIS (2009-2013) TB were calibrated using F13 TB as the baseline, and the calibrated F17 TB data were denoted as F13C TB data, which were used to calculate F13C SD. Furthermore, the original F17 SD and F13C SD were compared with the OIB SD during 2009-2013.

Figure 4 shows the difference between the F17 SD, the F13C SD and the OIB SD on first-year sea ice. The Bias and RMSE can be calculated using the following formulas: BIAS $=\sum_{i=1}^{n}\left(h_{i}-O_{i}\right) / n$, and $R M S E=\sqrt{\sum_{i=1}^{n}\left(h_{i}-O_{i}\right)^{2} / n}$, where $h_{i}$ refers to the value of F17 (F13C) SD for each pixel, and $O_{i}$ refers to the value of OIB SD for the same pixel, $n$ is the number of pixels. The values of Bias and RMSE between the F17 and the OIB SDs are $-9 \mathrm{~cm}$ and $10 \mathrm{~cm}$, respectively. These values are larger than those that were obtained by comparison of the F13C SD with the OIB SD, indicating that F17 SSMIS calibrated to F13 SSM/I is more suitable for obtaining a long-time series SD.

Table 5 shows the yearly bias and RMSE values of the F13C SD to the OIB SD from 2009 to 2013. The absolute Bias and RMSE of the F13C-OIB SD are much smaller than the F17-OIB SD. 

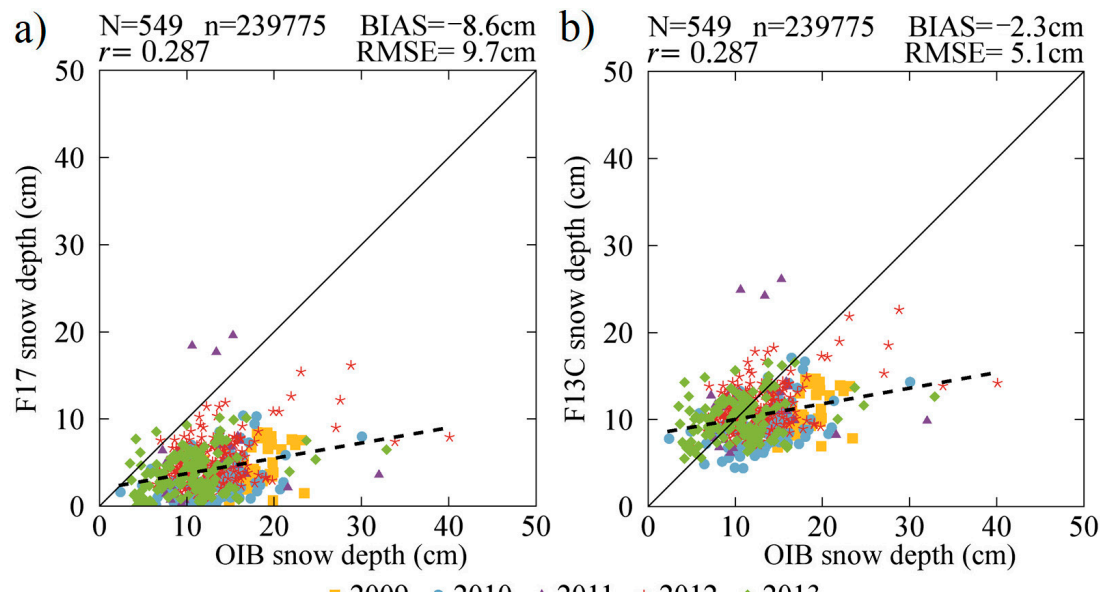

Figure 4. Comparison between satellites derived SD and OIB measured SD: (a) F17 snow depth vs. OIB snow depth; (b) F13C snow depth vs. OIB snow depth. F13C snow depths are derived from F13C TB which are the result of F17 TB calibrated to F13 using CA models according to Cavalieri et al. [19]. The solid line is the one-to-one fitting line, and the dashed line is the regression line of F17 or F13C to OIB snow depth and $r$ refers to the correlation coefficient; $\mathrm{N}$ refers to the pixel's number, and $\mathrm{n}$ presents the total OIB snow depth records in those pixels.

Table 5. Bias (B) and root mean square error (RMSE) of F17 SD minus OIB SD (F17 SD-OIB SD) and F13C SD minus OIB SD (F13C SD-OIB SD) during OIB spring campaigns in 2009, 2010, 2011, 2012 and 2013. F13C SDs are derived from F13C TB which are the result of F17 TB calibrated to F13 using CA models according to Cavalieri et al. [19]. $\mathrm{N}$ is the number of pixels.

\begin{tabular}{cccccc}
\hline \multirow{2}{*}{ Year } & \multirow{2}{*}{$\mathbf{N}$} & \multicolumn{2}{c}{ F17 SD-OIB SD } & \multicolumn{2}{c}{ F13C SD-OIB SD } \\
\cline { 3 - 6 } & & B (cm) & RMSE (cm) & B (cm) & RMSE (cm) \\
\hline 2009 & 66 & -13.5 & 13.7 & -7.7 & 7.4 \\
2010 & 101 & -10.4 & 11.0 & -4.1 & 5.4 \\
2011 & 30 & -6.7 & 9.4 & -0.4 & 6.7 \\
2012 & 215 & -7.8 & 8.8 & -1.6 & 4.2 \\
2013 & 137 & -6.5 & 7.8 & -0.3 & 4.3 \\
Total & 549 & -8.6 & 9.7 & -2.3 & 5.1 \\
\hline
\end{tabular}

\section{Discussion}

F13 SSM/I sensor's feature is similar to F17 SSMIS, with the mean biases of measured brightness temperatures for the channel of $19 \mathrm{~V}, 19 \mathrm{H}, 22 \mathrm{~V}$ and $37 \mathrm{~V}$ vary from $0.8 \mathrm{~K}$ to $1.7 \mathrm{~K}$ in 2007 . These minor discrepancy of TB lead to $0.5 \%$ bias for the calculated sea ice concentration, and have a profound impact on GRV (ice) in SD retrieval algorithm, finally resulting in $-6.7 \mathrm{~cm}$ bias for the calculated SD (Table 6), in addition, Figure 5 shows the significant differences of derived SD from F13 TB and the uncorrected F17 TB, despite the SD retrieval algorithm breaks down in summer due to the snow is wet or exists a certain liquid water fraction. Therefore, the inter-calibration processing between F13 TB and F17 TB is necessary for deriving long-term snow depth.

Table 6. Bias (B), mean relative error (MRE) and root mean square error (RMSE) of SIC, GRV, and SD between F13, F17 and F13C in 2007. The SIC, GRV and SD of F13C are derived from F13C TB which are the result of F17 TB calibrated to F13 TB using CA models according to Cavalieri et al. [19].

\begin{tabular}{lccccccccc}
\hline \multirow{2}{*}{ Comparison } & \multicolumn{3}{c}{ Sea Ice Concentration } & \multicolumn{3}{c}{ GRV (ice) } & \multicolumn{3}{c}{ Snow Depth } \\
\cline { 2 - 10 } & B (\%) & MRE (\%) & RMSE (\%) & B & MRE (\%) & RMSE & B (cm) & MRE (\%) & RMSE (cm) \\
\hline F17-F13 & 0.5 & 0.7 & 0.6 & -0.7 & -89.2 & 2.4 & -6.6 & 38.5 & 6.7 \\
F13C-F13 & 0.1 & 0.1 & 0.3 & 0.7 & 1.0 & 2.3 & -0.4 & -4.6 & 0.7 \\
\hline
\end{tabular}




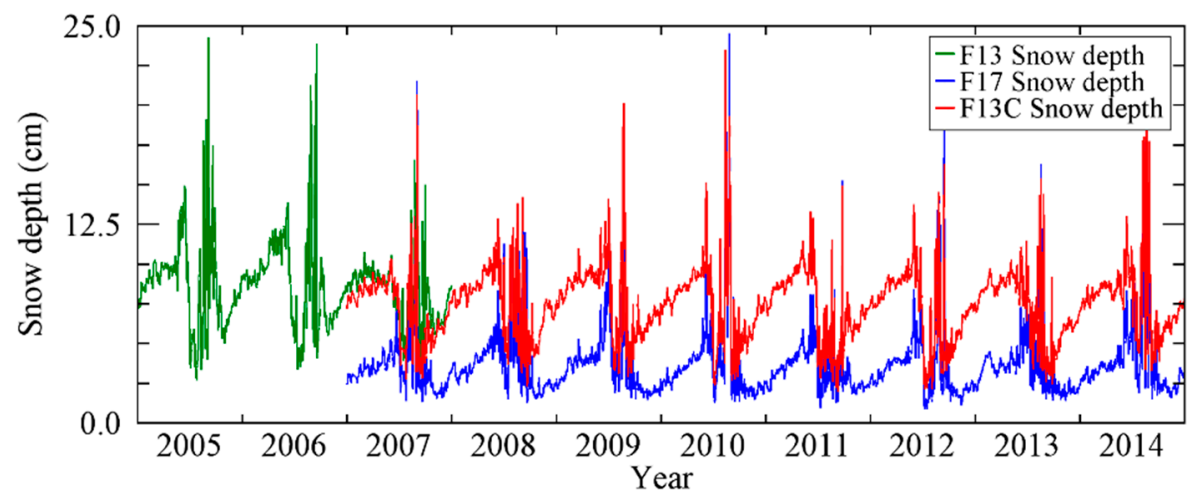

Figure 5. Comparison among F13 SD, F17 SD and F13C SD. F13 SD from 2005 to 2007 are drawn in green line, F17 SD from 2007 to 2014 are drawn in blue line, and F13C SD from 2007 to 2014 are drawn in red line.

The F13C TB were the result that F17 TB calibrated to F13 TB using CA models according to Cavalieri et al. [19]. When comparing with F17 to F13, there are lower biases for sea ice concentration, GRV (ice) and SD between F13C and F13. The bias of $-6.6 \mathrm{~cm}$ exists between F17 SD and F13 SD, and $-0.4 \mathrm{~cm}$ between the F13C SD and F13 SD, which mean that F13C SD is about $6.2 \mathrm{~cm}$ higher than F17 SD. Moreover, the $6.2 \mathrm{~cm}$ bias is as the same as the F13C cloud points seem to be higher than that of F17 cloud points in Figure 4. In the similar way, we derived SD from the TB which originates from the TB result of F17 TB calibrated to F13 TB using DA models, and then compared with F13 SD in 2007. The bias, RMSE and MRE between the two SD are $-0.5 \mathrm{~cm}, 0.8 \mathrm{~cm}$ and $-6.2 \%$, respectively. It can be concluded that CA models seem a little better than DA models when inter-calibrating F13 TB and F17 TB for the snow depth retrieval purpose.

The calibration method following Cavalieri et al. [19] was ultimately used in this paper, due to the smaller RMSE values when comparing to that of the method from Dai et al. [20] (Table 3) and the SD retrievals using CA models were better agree with F13 SD. Furthermore, DA models according to Dai et al. [20] is used for terrestrial snow cover and the Cavalieri method is used specifically for sea ice. The linear coefficients were obtained through the relationship between the F13 TB and F17 TB for each channel for the entire year in DA models, and the daily sample points will affect the regression coefficients directly. However, the linear regression coefficients between the F13 TB and F17 TB were obtained for each day on each channel, and then the daily coefficients values were averaged to produce coefficient values as the final coefficient in CA models. This processing reduced the direct impact of daily sample points on the final coefficient value, but increased the amount of calculations.

The OIB SD variability within a $25 \mathrm{~km}$ pixel in this paper is different from the values reported by Brucker et al. [10], who analyzed the two $12.5 \mathrm{~km}$ pixels of the two OIB SD transects over multiyear ice, with the mean SDs differing by 2-4 cm on 18 March 2011, whereas, the mean SDs differing by 1-3 cm on first-year sea ice was found in this study. The RMSE of F13C SD when compared with OIB SD is $5 \mathrm{~cm}$, which is less than that in Brucker et al. [10], with the RMSE of $7 \mathrm{~cm}$ for the comparison of SDs that was acquired by the AMSR-E with the OIB SD.

Through comprising the F17 SDs, F13 SDs with the OIB SDs, we conclude that it is more suitable to choose the F13 SSM/I TB as the baseline for the SD retrieval purpose on the Arctic sea ice. However, Dai et al. [20] recommended using the F17 SSMIS TB as the reference to improve the consistency between F13 SSM/I TB and F17 SSMIS TB when comparing the retrieved snow depth over Tibetan Plateau. We conclude that the calibration option should be adjusted according to the different retrieval parameters for different regions.

The change of Arctic sea ice to a thinner and seasonal one, may result in a smaller and faster moving ice cover and snow-ice formation than just a decade ago [30,31]. Wet snow and melt-ice will bring large retrieval error based on the existing SD empirical algorithm [8], which may influence the 
inter-calibration option of SSM/I and SSMIS TB data. It is necessary to reconstruct the SD retrieval model using the field-derived SD measurements. Some international Arctic research initiatives like the MOSAiC science plan [32] are broadly motivated by the dramatic changes in the Arctic climate system. More snow depth measurements on first-year sea ice could be collected to build a robust new snow depth algorithm based on passive microwave satellite data, for obtaining more consistent snow depth information over Arctic first-year ice.

\section{Conclusions}

This paper attempted to construct a consistent time-series data set of brightness temperatures through establishing the calibration models for the four channels. We further compared SDs on Arctic first-year sea ice that was derived from passive microwave satellite observations of the SSM/I and SSMIS with the OIB SDs.

Inter-calibration model analysis show that the RMSE of the DA models are higher than that of the CA models for the channel of $19 \mathrm{H}, 19 \mathrm{~V}, 22 \mathrm{~V}$, whereas the RMSE of CA models is higher than that of DA models for the 37V channel. Taking into account of the overall effect, the CA models are recommended to correct the inter-sensor bias.

The variations of OIB SD are 5-7 cm while examining the OIB transect across the $25 \mathrm{~km}$ pixel on 15 and 17 March 2012, with 1-3 cm SD deviation for two transects in different locations.

Based on CA models, the biases between the retrieved F17 SDs and F13C SDs when compared to the OIB SDs are both around $-8 \sim-2 \mathrm{~cm}$. In addition, the F13C SDs perform smaller RMSE $(5 \mathrm{~cm})$ than F17 $(10 \mathrm{~cm})$. It can be concluded that TB observations from F17 SSMIS calibrated to F13 SSM/I as the baseline should be recommended when performing the sensors' biases correction for snow depth purpose based on the existing algorithm.

Snow depth over Arctic sea ice is an important parameter for calculating ice thickness. Inter-sensor calibration can reduce the systematic errors that are introduced by the use of various passive microwave sensors, and it can improve the consistency of SD time-series data that are used for long-term trend analyses. However, the calibration models in different Arctic sea regions could also be considered for future studies in order to obtain SD information with greater accuracy and consistency. Currently, NASA MEaSUREs program produces an improved, enhanced-resolution, gridded passive microwave data set [33], it means that higher-resolution PM data can be used for future studies of obtaining accurate SD information, as well as Arctic sea ice thickness.

It should be noted that the SD empirical algorithm may influence the inter-calibration option, however, there are no other SD algorithms expect for the Markus's empirical algorithm published in 1998 based on DMSP SSM/I-SSMIS TB data until now. More in-situ SD measurements over first-year sea ice should be collected to construct a robust new SD algorithm in future work. However, this paper provided an inter-calibration option about obtaining more consistent SD information based on the existing algorithm.

Acknowledgments: The authors would like to thank the National Snow and Ice Data Center, Brigham Young University, Cold Region Research and Engineer Laboratory for providing SSM/I, SSMIS brightness temperature data, QuikSCAT, ASCAT sea-ice type data and in situ snow depth measurements. The authors acknowledge the joint support from the National Key Research and Development Program of China (2016YFC1402704, 2017YFA0603104), the National Natural Science Foundation of China $(41576188,41606215)$, the fund of Key Laboratory of Polar Science, SOA (PS1502), the Chinese Postdoctoral Science Foundation Funded Project (2016M602342) and the Fundamental Research Funds for the Central Universities (2042016kf0038). Comments from the anonymous referees and the editor are also gratefully appreciated.

Author Contributions: Qing Ji and Xiaoping Pang designed the experiments, and Qingquan Liu wrote the paper under the supervision of Qing Ji and Ruibo Lei. Qingquan Liu and Qing Ji analyzed the experimental data. Xin Gao and Xi Zhao contributed to the preparation of the compared results. All authors were involved in the modification of the paper and the discussion of the results.

Conflicts of Interest: The authors declare no conflict of interest. 


\section{References}

1. Stocker, T.F.; Qin, D.; Plattner, G.-K.; Tignor, M.; Allen, S.K.; Boschung, J.; Nauels, A.; Xia, Y.; Bex, B.; Midgley, B. IPCC, 2013: Climate Change 2013: The Physical Science Basis. Contribution of Working Group I to the Fifth Assessment Report of the Intergovernmental Panel on Climate Change; Cambridge University Press: Cambridge, UK, 2013.

2. Meier, W.N.; Hovelsrud, G.K.; Oort, B.E.H.; Key, J.R.; Kovacs, K.M.; Michel, C.; Haas, C.; Granskog, M.A.; Gerland, S.; Perovich, D.K. Arctic sea ice in transformation: A review of recent observed changes and impacts on biology and human activity. Rev. Geophys. 2015, 52, 185-217. [CrossRef]

3. Stroeve, J.C.; Serreze, M.C.; Holland, M.M.; Kay, J.E.; Malanik, J.; Barrett, A.P. The Arctic's rapidly shrinking sea ice cover: A research synthesis. Clim. Chang. 2012, 110, 1005-1027. [CrossRef]

4. Bhatt, U.S.; Walker, D.A.; Walsh, J.E.; Carmack, E.C.; Frey, K.E.; Meier, W.N.; Mo-Ore, S.E.; Parmentier, F.J.W.; Post, E.; Romanovsky, V.E. Implications of Arctic Sea Ice Decline for the Earth System. Annu. Rev. Environ. Resour. 2014, 39, 57-89. [CrossRef]

5. Nghiem, S.; Rigor, I.; Perovich, D.; Clemente-Colón, P.; Weatherly, J.; Neumann, G. Rapid reduction of Arctic perennial sea ice. Geophys. Res. Lett. 2007, 34. [CrossRef]

6. Maslanik, J.; Stroeve, J.; Fowler, C.; Emery, W. Distribution and trends in Arctic sea ice age through spring 2011. Geophys. Res. Lett. 2011, 38. [CrossRef]

7. Dietz, A.J.; Kuenzer, C.; Gessner, U.; Dech, S. Remote sensing of snow-A review of available methods. Int. J. Remote Sens. 2012, 33, 4094-4134. [CrossRef]

8. Markus, T.; Cavalieri, D.J. Snow Depth Distribution Over Sea Ice in the Southern Ocean from Satellite Passive Microwave Data; American Geophysical Union: Washington, DC, USA, 1998; Volume 74, pp. 19-39.

9. Perovich, D.K.; Polashenski, C. Albedo evolution of seasonal Arctic sea ice. Geophys. Res. Lett. $2012,39$. [CrossRef]

10. Brucker, L.; Markus, T. Arctic-scale assessment of satellite passive microwave-derived snow depth on sea ice using Operation IceBridge airborne data. J. Geophys. Res. Oceans 2013, 118, 2892-2905. [CrossRef]

11. Webster, M.A.; Rigor, I.G.; Nghiem, S.V.; Kurtz, N.T.; Farrell, S.L.; Perovich, D.K.; Sturm, M. Interdecadal changes in snow depth on Arctic sea ice. J. Geophys. Res. Oceans 2014, 119, 5395-5406. [CrossRef]

12. Kern, S.; Khvorostovsky, K.; Skourup, H.; Rinne, E.; Parsakhoo, Z.; Djepa, V.; Wadhams, P.; Sandven, S. The impact of snow depth, snow density and ice density on sea ice thickness retrieval from satellite radar altimetry: Results from the ESA-CCI Sea Ice ECV Project Round Robin Exercise. Cryosphere 2015, 9, 37-52. [CrossRef]

13. Giles, K.; Laxon, S.; Wingham, D.; Wallis, D.; Krabill, W.; Leuschen, C.; McAdoo, D.; Manizade, S.; Raney, R. Combined airborne laser and radar altimeter measurements over the Fram Strait in May 2002. Remote Sens. Environ. 2007, 111, 182-194. [CrossRef]

14. Justice, C.; Belward, A.; Morisette, J.; Lewis, P.; Privette, J.; Baret, F. Developments in the 'validation' of satellite sensor products for the study of the land surface. Int. J. Remote Sens. 2000, 21, 3383-3390. [CrossRef]

15. Chander, G.; Hewison, T.J.; Fox, N.; Wu, X.; Xiong, X.; Blackwell, W.J. Overview of intercalibration of satellite instruments. IEEE Trans. Geosci. Remote Sens. 2013, 51, 1056-1080. [CrossRef]

16. Abdalati, W.; Steffen, K.; Otto, C.; Jezek, K. Comparison of brightness temperatures from SSMI instruments on the DMSP F8 and F11 satellites for Antarctica and the Greenland ice sheet. Int. J. Remote Sens. 1995, 16, 1223-1229. [CrossRef]

17. Stroeve, J.; Maslanik, J.; Xiaoming, L. An intercomparison of DMSP F11-and F13-derived sea ice products. Remote Sens. Environ. 1998, 64, 132-152. [CrossRef]

18. Meier, W.N.; Khalsa, S.J.S.; Savoie, M.H. Intersensor Calibration between F-13 SSM/I and F-17 SSMIS Near-Real-Time Sea Ice Estimates. IEEE Trans. Geosci. Remote Sens. 2011, 49, 3343-3349. [CrossRef]

19. Cavalieri, D.J.; Parkinson, C.L.; Digirolamo, N.; Ivanoff, A. Intersensor Calibration between F13 SSMI and F17 SSMIS for Global Sea Ice Data Records. IEEE Geosci. Remote Sens. Lett. 2012, 9, 233-236. [CrossRef]

20. Dai, L.; Che, T.; Ding, Y. Inter-calibrating SMMR, SSM/I and SSMI/S data to improve the consistency of snow-depth products in China. Remote Sens. 2015, 7, 7212-7230. [CrossRef]

21. Anderson, S. Monitoring the marginal ice zone with HF radar. In Proceedings of the 2017 IEEE Radar Conference, Seattle, WA, USA, 8-12 May 2017; pp. 289-293. 
22. Maslanik, J.; Stroeve, J. DMSP SSM/I-SSMIS Daily Polar Gridded Brightness Temperatures, Version 4; NASA National Snow and Ice Data Center Distributed Active Archive Center: Boulder, CO, USA, 2004; Available online: https: / / n5eil01u.ecs.nsidc.org/ICEBRIDGE/IDCSI4.001.html (accessed on 17 September 2017).

23. Kurtz, N.T.; Farrell, S.L. Large-scale surveys of snow depth on Arctic sea ice from Operation IceBridge. Geophys. Res. Lett. 2011, 38, 582. [CrossRef]

24. Kurtz, N.T.; Farrell, S.L.; Studinger, M.; Galin, N. Sea ice thickness, freeboard, and snow depth products from Operation IceBridge airborne data. Cryosphere 2013, 7, 1035-1056. [CrossRef]

25. Kurtz, N.; Studinger, M.; Harbeck, J.; Onana, V.; Yi, D. IceBridge L4 Sea Ice Freeboard, Snow Depth, and Thickness, Version 1; Boulder, Colorado USA; NASA National Snow and Ice Data Center Distributed Active Archive Center: Boulder, CO, USA, 2015; Available online: https:/ /n5eil01u.ecs.nsidc.org/ICEBRIDGE/IDCSI4.001.html (accessed on 17 September 2017).

26. Markus, T.; Cavalieri, D.J. AMSR-E Algorithm Theoretical Basis Document: Sea Ice Products; NASA: Greenbelt, MD, USA, 2008.

27. Cavalieri, D.J.; Gloersen, P.; Campbell, W.J. Determination of sea ice parameters with the Nimbus 7 SMMR. J. Geophys. Res. Atmos. 1984, 89, 5355-5369. [CrossRef]

28. Comiso, J.C.; Cavalieri, D.J.; Markus, T. Sea ice concentration, ice temperature, and snow depth using AMSR-E data. IEEE Trans. Geosci. Remote Sens. 2003, 41, 243-252. [CrossRef]

29. Harbeck, J. Arctic Snow Depth on Sea Ice. Available online: https://neptune.gsfc.nasa.gov/csb/index.php? section=53 (accessed on 17 September 2008).

30. Richter-Menge, J.A.; Perovich, D.K.; Elder, B.C.; Claffey, K.; Rigor, I.; Ortmeyer, M. Ice mass-balance buoys: A tool for measuring and attributing changes in the thickness of the Arctic sea-ice cover. Ann. Glaciol. 2006, 44, 205-210. [CrossRef]

31. Vihma, T.; Pirazzini, R.; Fer, I.; Renfrew, I.A.; Sedlar, J.; Tjernström, M.; Lüpkes, C.; Nygard, T.; Notz, D.; Weiss, J. Advances in understanding and parameterization of small-scale physical processes in the marine Arctic climate system: A review. Atmos. Chem. Phys. 2014, 14, 9403-9450. [CrossRef]

32. Dethloff, K.R.; Shupe, M. Multidisciplinary Drifting Observatory for the Study of Arctic Climate (MOSAiC); International Arctic Sience Committee: Akureyri, Iceland, 2016.

33. Brodzik, M.J.; Long, D.G.; Hardman, M.A.; Paget, A.; Armstrong, R. MEaSUREs Calibrated Enhanced-Resolution Passive Microwave Daily EASE-Grid 2.0 Brightness Temperature ESDR, Version 1; NASA National Snow and Ice Data Center Distributed Active Archive Center: Boulder, CO, USA, 2016. 